\title{
Are Supporting Sectors of the Creative Industries Inferior? Current study from Slovakia.
}

\author{
Mária Kmety Barteková ${ }^{1, *}$, Helena Majdúchová ${ }^{1}$ \\ ${ }^{1}$ University of Economics, Faculty of Business Management, Department of Business Economy, \\ Dolnozemská cesta 1, 85235 Bratislava, Slovakia
}

\begin{abstract}
The aim of the contribution is to analyse the current state of the supporting sectors within the creative industries, to identify and quantify the role of the supporting sectors in the Slovak economy. In the European union, there are huge expectations associated with the creative industries. Based on the following findings, we can conclude that the low level of external investments is caused by the low possibility to get the loans. There is no relation between the regional density of supporting sectors' enterprises and the economic results reached by these regions.
\end{abstract}

\section{Introduction}

The well-known authors and researchers $[1,2,3,4]$ tried to considerate a new aspect, that is, the multidimensional nature of creativity and the potential synergic and complementary effects of creative talents of different nature. The merging of talents is, indeed, a source of original, complex and synergic ideas which are at the basis of the positive relation between creativity and local development.

The objectives of the first companion of cultural economists - a few of them are even in our midst-were good. They wanted to prove all other economists that their mechanisms are applicable in a study of the arts, too, and looked for recognition for their exercise. At the same moment they expected to influence cultural policy, bringing in a much needed economic perspective $[5,6]$. Maybe some hoped to influence the world of economists as well.

The motivation for the value-based approach came about in the study of the world of the arts. As many of us have experienced, people in that world do not take easy to the standard economic approach. The value-based approach begins with what theater makers and others involved in the arts world find important, that is with their values, or with the qualities that they want to realize. Usually those values, or qualities, are artistic in kind; they concern theatrical or musical or multimedial qualities. Often they will mention social and societal values, like when they want to contribute to local communities, social cohesion, justice and such [7]. While using relevant economic policy tools, the state at national, regional and

\footnotetext{
* Corresponding author: maria.bartekova@euba.sk
} 
local levels may help to rise creative industries in general by determining priorities for the socio economic development [2].

This is a useful starting point because it allows us to focus attention on the relational nature of processes of value allocation and cultural validation: cultural value does not operate and is not generated in a social, cultural and political vacuum, but is in fact shaped by the power relations predominant at any one time, and is a site for struggles over meaning, representation and recognition [8].

Creative industries are in a strategic position to promote smart, sustainable and inclusive growth in all EU regions and cities, and thus contribute fully to the Europe 2020 Strategy, which is the EU's growth strategy [9]. While some EU regions have been very good at tapping into this extraordinary potential as a way to promote socio-economic development including through the use of EU Structural Funds -, it however appears that many others have not been making most of this potential.

\section{Methods}

The following chapter provides the information about research aim, the detail description of the research object and the methodology used in this paper.

The aim of the paper is to research the specifics of the supporting sectors of the creative industries. In the paper, we articulated the following research questions:

- Research question no. 1: Are supporting sectors of the creative industries inferior?

- Research question no. 2: Have the supporting sectors of the creative industries reported the weak results in the selected indicators (the debt level, the share of the bankrupted entities, etc.)?

- Research question no. 3: Are the clusters with the highest amount of supporting sectors' enterprises located in the regions with the highest GDP per capita?

Supporting sectors of the creative industries include the following business activities according to the numeral classification provided by the Statistical Office of the Slovak Republic:

- Other professional scientific and technical activities - SK NACE code 74.900

- Organization of congresses and business exhibitions - SK NACE code 82.300

- Artistic education - SK NACE code 85.520

- Stage - related supporting activities - SK NACE code 90.020.

We collected the information about all enterprises, which are active in Slovakia and belong under the selected SK NACE codes. SK NACE represents statistical classification of economic activities in the Slovak Republic.

The most valuable sources were founded in the scientific database Web of Science. We focused on the Q1 and Q2 - ranked journals in management, innovation, economics, business research and regional studies.

To fulfil the research aim, we collected the information about the enterprises belonging to the supporting sectors of the creative industries in the Slovak Republic. The data used in the research were provided by the Statistical Office of the Slovak Republic, Finstat and Eurostat. To find the answers for the research questions, we used the descriptive statistics.

\section{Results and Discussion}

Creative industries (supporting sectors included), in particular SMEs, encounter difficulties in accessing the funds they need to finance their activities, both in terms of credit and equity. While this is a common challenge for SMEs in general, the situation is significantly worse for those working in the creative sectors for the following reasons: 
- unlike other industrial products, creative industries' products are generally not massproduced;

- in most cases the financial requirements of creative industries' companies are not substantial enough for banks to find them commercially interesting enough to undertake the analyses of projects,

- creative industries also face specific challenges in achieving investment readiness, in particular at a time when they have to find innovative business models for the new digital environment.

One can see the summary of the financial results in the table 1 . The debt ratio of the supporting sectors' enterprises reached in average $40 \%$. As it was mentioned before, the supporting sectors of the creative industries are not substantial for banks. In most of the cases the banks reject the applications for the business loans.

Table 1. Financial characteristics of the supporting sectors' entities in Slovakia.

\begin{tabular}{|l|c|c|c|c|c|}
\hline \multicolumn{1}{|c|}{ Variable } & N & Mean & Std Dev & Minimum & Maximum \\
\hline Assets & 236 & 67733.88 & 190934.46 & 1196.00 & 2272275.00 \\
\hline Equity & 236 & 30749.53 & 129188.65 & -92412.00 & 1828241.00 \\
\hline Debt ratio & 236 & $40.37 \%$ & $47.78 \%$ & $-4.24 \%$ & $350.66 \%$ \\
\hline
\end{tabular}

Culture and creative-based development has relevance for regions in all stages of development - in the 'convergence' regions, where support for infrastructural development may continue to be needed, but also in both convergence and 'competitiveness' regions where the infrastructure and other local resources can be exploited to enhance the comparative advantages of the local economy and to stimulate creativity and enterprise [10].

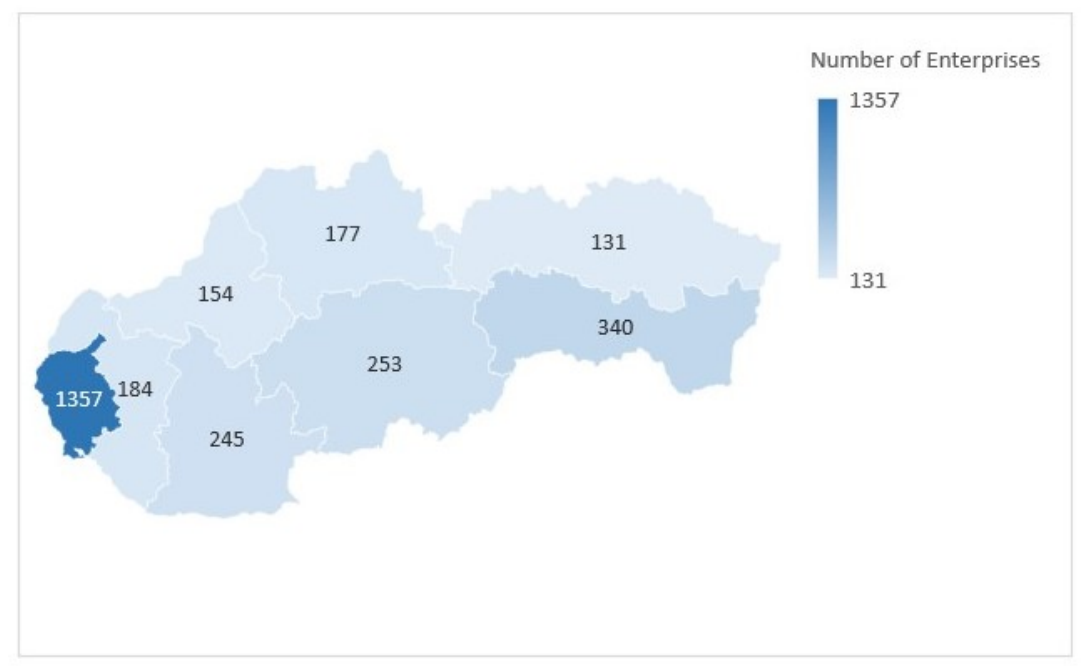

Fig. 1. Regional location of the supporting sectors' entities of the creative industries

Source: own processing, data extracted from Finstat database (2018).

Figure 1 represents the regional density of the supporting sectors' enterprises in Slovakia. The cluster with the highest density of the mentioned enterprises is the Bratislava region (1357 enterprises). The second one is the Košice region with the number of enterprises 340 [11]. 


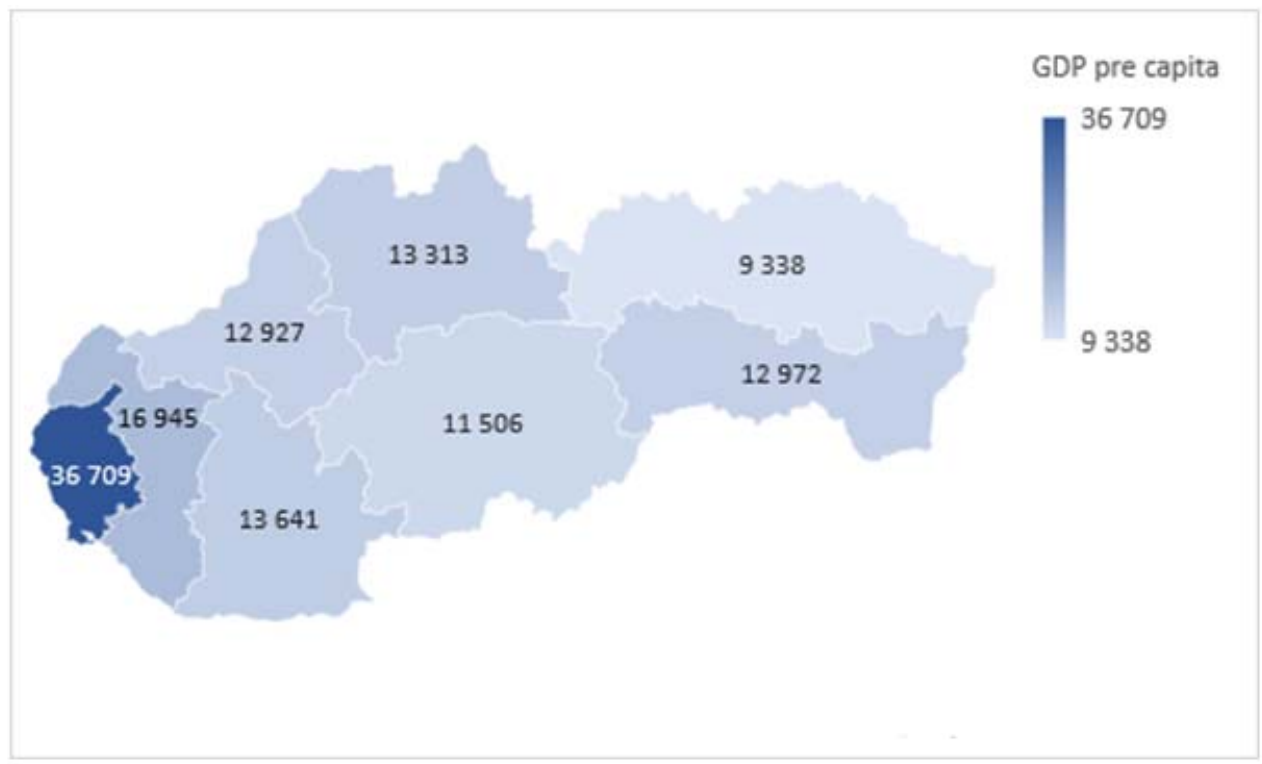

Fig. 2. Regional Differences in Slovakia measured by the indicator GDP per capita

Source: own processing, data extracted from the Statistical Office of the Slovak Republic database (2018).

The most creative regions are characterized by having more high-tech manufacturing industries than the rest of the regions although the number of low-tech manufacturing firms is similar. Lastly, the industrial structure of each region has a greater influence on regional wealth than the existence of industrial agglomerations [12].

In many regions the creative sector is rapidly growing, outperforming other more established sectors in terms of growth in new businesses, turnover and employment; in many instances the absolute size of the sector now exceeds that of a range of traditional industries. Many cities and regions have some form of creative sector strategy; the focus and detail of this strategy, however, vary considerably; in the most developed regions the promotion of the creative sector is part and parcel of a strategy for knowledge-based industries. As well as its inherent dynamism and growth potential, the creative sector has a number of other attractive qualities from a local development perspective; it makes use of a range of skills at a series of different levels, it tends to be socially responsible and inclusive and it usually involves 'clean', environmentally friendly processes. The region with the highest GDP is also a region with the highest density of the supporting sectors' enterprises - the Bratislava region. One can see that the rest of regions in Slovakia has the similar number of enterprises (figure 2). We can't prove the relation that the clusters with the highest number of the supporting sectors' enterprises are located in the regions with the highest GDP per capita.

In more technical terms, creative activities often generate positive externalities in the areas where they are located, their openness and interaction with other activities give rise to agglomeration and cluster effects and they tend to generate a high proportion of total value added locally. A longer-term and more strategic approach to culture-based development is required at a local and regional level. This should be mainstreamed into development strategies that are integrated and built on partnerships between public authorities, cultural organisations, the relevant business interests and representatives of civil society. 


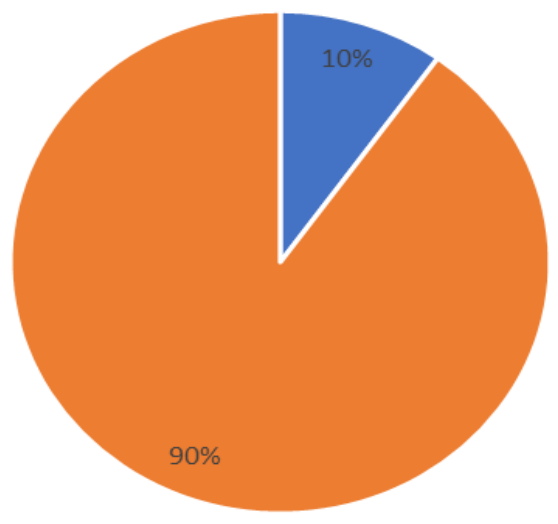

- With debt

- No debt

Fig. 3. External sources in the capital structure of the supporting sectors' enterprises.

Source: own processing, data extracted from Finstat database (2018).

The enterprises operating in the supporting sectors of the creative industries are using mainly the own financial sources as the own equity. One can see only $10 \%$ of the all enterprises used the external sources of financing their activities or projects (see Figure 3).

Before the corona crisis have begun, more than $99 \%$ of enterprises were financially stable in 2018 (Figure 4). The supporting sectors of the creative industries consists of 2841 enterprises in Slovakia [13]. Only a few enterprises operating the supporting sectors were abolished or under restructuring $(0.45 \%)$.

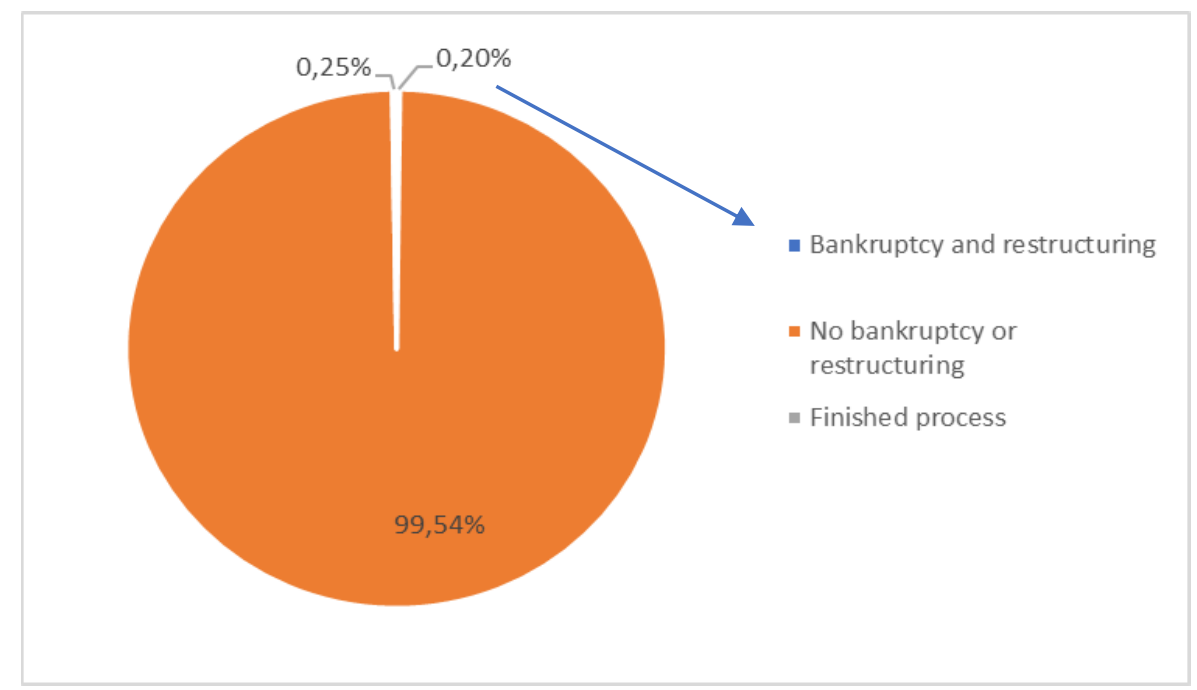

Fig. 4. The financial wealth of the enterprises in the supporting sectors.

Source: own processing, data extracted from Finstat database (2018).

Figure 5 shows the ownership structure of the supporting sectors' enterprises in the Slovak Republic. Most of the enterprises (around 89\%) has the domestic private ownership. 
The second biggest group of enterprises (the enterprises with the foreign ownership) reached $7 \%$.

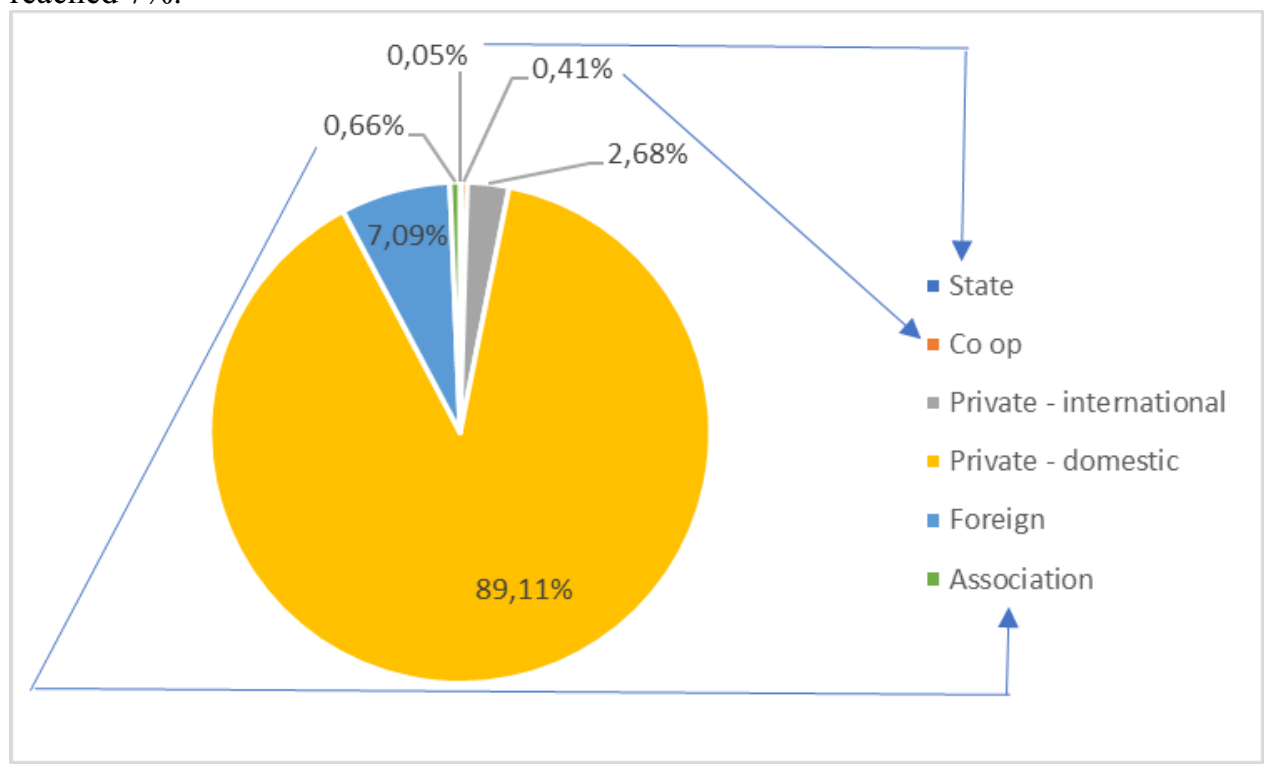

Fig. 5. The ownership structure of the supporting sectors' enterprises in Slovakia.

Source: own processing, data extracted from Finstat database (2018).

Against this background, there is a crucial role to be played by public authorities particularly regional authorities - in stimulating private investment and promoting public private partnerships for the benefit of their Creative industries' SMEs, notably through guarantee mechanisms or venture capital funds $[14,15]$.

In the last section of this paper, we have provided the main conclusions.

\section{Conclusion}

Based on the finding stated above, we can conclude that the most of the enterprises operating in supporting sectors of the creative industries are own by the domestic owners. The reason is simple. In most cases the financial requirements of Creative industries' companies are not substantial enough for banks to find them commercially interesting enough to undertake the analyses of projects, then develop their expertise in a field that is still perceived as risky and build up specialised Creative industries departments able to understand the special business models of creative industries (supporting sectors included).

From this point of view, the supporting sectors' enterprises are inferior for the banks as the clients. The financial structure of these companies is influenced by the lack of external financial sources. The main source of the capital is their own equity. One can see that the assets of the supporting sectors' enterprises are lower than in the manufacturing industries.

This paper is the output of the scientific grant VEGA n. 1/0340/19 "The Entrepreneurial Dimension of Creative industries in the Context of Innovation and Smart Growth" (50\%) and the internal grant project of the University of Economics in Bratislava (Faculty of Business Management) no. I-20-10100 called "Research of Creative Industry Enterprises with regard to Their Life Cycle in the Slovak Republic" (50\%).

\section{References}


1. S. Cerisola, A new perspective on the cultural heritage-development nexus: the role of creativity. Journal of Cultural Economics, 43, 21-56 (2019)

2. A. Drab-Kurowska, State intervention in the context of creative industries. Management - Poland, 22, 74-84 (2018)

3. S. Cerisola, Creativity and local economic development: the role of synergy among different talents. Papers in Regional Science, 97, 199 - 209 (2018)

4. A. Lemmetyinen, Entrepreneurship in culture and creative industries: perspectives from companies and regions. International Small Business Journal - Researching Entrepreneurship, 37, 417-418 (2019)

5. Y. Wijngaarden, E. Hitters, P.V. Bhansing, 'Innovation is a dirty word': contesting innovation in the creative industries. International Journal of Cultural Policy, 25, 392-405 (2019)

6. W. Yu, Creative industries agglomeration and entrepreneurship in China: necessity or opportunity? Industry and Innovation, 27, 420-443 (2020)

7. XQ. Li, D. Gagliardi, I. Miles, Innovation in R\&D service firms: evidence from the UK. Technology Analysis \& Strategic Management, 31, 732-748 (2019)

8. E. Belfiore, Whose cultural value? Representation, power and creative industries. International Journal of Cultural Policy, 26, 383-397 (2020)

9. F. Angelini, M. Castellani, Cultural and economic value: a critical review. Journal of Cultural Economics, 43, 173-188 (2019)

10. R. Boix, B. De-Miguel-Molina, J. L. Hervas-Oliver, Creative service business and regional performance: evidence for the European regions. Service Business, 7, 381 -398 (2013)

11. The Statistical Office of the Slovak Republic, (2020, 25 March). Enterprise births in the SR by NACE Rev. 2 and size class category by number of employees. Retrieved from http://datacube.statistics.sk/\#!/view/sk/VBD_SLOVSTAT/og2005rs/v_og2005rs_ 00_00_00_sk.

12. Eurostat, (2020, 24 March). Value added and turnover of enterprises in the cultural sectors by NACE Rev. 2 activity. Retrieved from https://appsso.eurostat.ec.europa.eu/nui/submitViewTableAction.do.

13. Finstat, (2020, 1 April). Firmy s finančnými údajmi - databáza hospodárskych výsledkov slovenských firiem. Retrieved from https://instat.sk/databazafinancnych-udajov.

14. T. Paris, S. Ben Mahmoud-Jouini, The process of creation in creative industries. Creativity and Innovation Management, 28, 403-419 (2019)

15. S. Kaymas, Globalization, Neoliberalism and Creative Industries: A Note on the Alternative Governance Proposition. Amme Idaresi Dergisi, 52, 79-114 (2019) 